\title{
A CONTRIBUIÇÃO DO ORÇAMENTO SIGILOSO PARA A EFICIÊNCIA DAS LICITAÇÕES E CONTRATAÇÕES PÚBLICAS: UMA ANÁLISE A PARTIR DAS DECISÕES DO TCU
}

\author{
THE CONTRIBUTION OF CONFIDENTIAL BUDGET TO THE \\ EFFICIENCY OF PUBLIC BIDDING AND CONTRACTING: AN \\ ANALYSIS BASED ON TCU DECISIONS
}

\section{LA CONTRIBUCIÓN DEL PRESUPUESTO SECRETO PARA LA EFICIENCIA DE LAS LICITACIONES Y CONTRATACIONES PÚBLICAS: UN ANÁLISIS BASADO EN LAS DECISIONES DEL TCU João Paulo Gualberto Forni * Marcelo Dias Varella**}

\begin{abstract}
1 Introdução. 2 Contexto Normativo. 3 O sigilo como instrumento para maior eficiência. 3.1 A contestação do pressuposto de desestímulo a conluios. 3.2 A confirmação do pressuposto da redução de preços. $4 \mathrm{O}$ sigilo como instrumento para maior eficiência antes do RDC. 5 O sigilo no RDC: a prevalência do princípio da eficiência sobre o da publicidade. $6 \mathrm{O}$ início da fase de negociação como momento ideal para a revelação do orçamento estimado. 7 A eficiência do sigilo com exceção para o regime de contratação integrada. 8 Conclusão. Referências.
\end{abstract}

\section{RESUMO}

A busca por mais eficiência no âmbito das licitações e das contratações públicas deu origem ao Regime Diferenciado de Contratações Públicas (RDC). Uma das inovações trazidas por essa norma é o sigilo dos orçamentos. O presente trabalho analisa a contribuição dessa prática para a eficiência das licitações e das contratações públicas, defendendo sua constitucionalidade e sua adequação do ponto de vista da teoria econômica e da jurisprudência do Tribunal de Contas da União (TCU), com exceção para o regime de contratação integrada. O texto faz uma análise crítica da teoria jurídica recente e das decisões do TCU e do Tribunal de

* Mestre em Direito Público pelo Centro Universitário de Brasília e Auditor Federal de Controle Externo no Tribunal de Contas da União. Brasília, DF, Brasil. E-mail: <joao.forni@gmail.com>.http://orcid.org/00000002-7872-9200

** Doutor e livre-docente em Direito e pesquisador do CNPq. Professor do Centro Universitário de Brasília. Brasília, DF, Brasil. E-mail: >marcelodvarella@gmail.com>.http://orcid.org/0000-0001-5538-0838 
Justiça da União Europeia sobre a efetividade dos modelos de contratação criados a partir das experiências com a Copa do Mundo e com as Olimpíadas. Conclui-se que, embora existam limites importantes nos modelos adotados, estes apresentam vantagens comparativas importantes em relação à lógica anterior.

Palavras-chave: Orçamento sigiloso. Licitações e contratações. Eficiência.

\begin{abstract}
The search for more efficiency in the field of public procurement gave rise to the Differential Public Procurement Regime (RDC, in Portuguese). One of the innovations brought by that norm is the secrecy in the budget-making process. This paper analyzes the contribution this practice offered to the efficiency of public procurement, defending its constitutionality and adequacy to the economic theory and jurisprudence of the $\mathrm{Fe}$ deral Court of Accounts (TCU, in Portuguese) except for the design-build model. The paper provides a critical analysis of recent legal theory and the decisions of the TCU and the Court of Justice of the European Union on the effectiveness of public procurement models created from experiences with the World Cup and the Olympics. It is concluded that, although there are important limits in the adopted models, they present important comparative advantages in relation to the previous logic.
\end{abstract}

Keywords: Secret budget-making process. Public procurement. Efficiency.

\title{
RESUMEN
}

La búsqueda por más eficiencia en el ámbito de las licitaciones y contrataciones públicas dio origen al Régimen Diferenciado de Contrataciones Públicas (RDC, en portugués). Una de las innovaciones traídas por esta norma es el secreto de los presupuestos. El presente trabajo analiza la contribución de esta práctica a la eficiencia de las licitaciones y contrataciones públicas, defendiendo su constitucionalidad y su adecuación desde el punto de vista de la teoría económica y de la jurisprudencia del Tribunal de Cuentas de Brasil (TCU), con excepción del régimen de contratación integrada. El texto hace un análisis crítico de la teoría jurídica reciente y de las decisiones del TCU y del Tribunal de Justicia de la Unión Europea sobre la efectividad de los modelos de contratación creados a partir de las experiencias con la Copa del Mundo y con las Olimpiadas. Se concluye que, aunque existan límites importantes en los modelos adoptados, los mismos presentan ventajas comparativas importantes en relación a la lógica anterior.

Palabras-clave: Presupuesto Secreto. Licitaciones y Contrataciones. Eficiencia. 


\section{INTRODUÇÃO}

O sigilo nas licitações é instrumento efetivo para a maior eficiência das licitações de menor complexidade. Contudo, não se pode dizer o mesmo de licitações que envolvam obras complexas, de grande vulto, o que leva a questionar as soluções generalizantes para todas as licitações.

Nesse contexto, o desafio da revisão do processo licitatório no Brasil está em encontrar fórmulas jurídicas para realizar contratos com custos mais baixos, que garantam a execução de obras e serviços em tempos menores e com maior qualidade. A redução das informações entre os concorrentes, a inversão de fases e a possibilidade de contratação integrada têm sido apresentadas como soluções para esses problemas. A questão da transparência versus efetividade em compras públicas é um problema recorrente em vários países e objeto de diversos casos nas cortes estrangeiras (SANCHEZ-GRAELLS, 2013).

No Brasil, nos últimos anos, em virtude dos grandes eventos promovidos no país, como Olimpíadas e Copa do Mundo, foi possível testar novas fórmulas para licitações, como o Regime Diferenciado de Contratação (RDC), que se expandiu para diferentes situações na sequência. A ideia deste artigo é avaliar a efetividade do sigilo dos orçamentos como uma das soluções propostas.

Introduzido pela Lei $\mathrm{n}^{\mathrm{o}} 12.462 / 2011$ e regulamentado pelo Decreto $\mathrm{n}^{\mathrm{O}} 7.581 / 2011$, o RDC foi inicialmente criado exclusivamente para licitações e contratos referentes aos Jogos Olímpicos e Paraolímpicos de 2016, à Copa das Confederações 2013 e à Copa do Mundo de 2014, sendo, posteriormente, estendido a diversas outras matérias ${ }^{1}$, o que afastou seu caráter de transitoriedade.

A Lei que disciplina o RDC traz a eficiência como princípio norteador ${ }^{2}$, além de proclamar, logo em seu art. $1^{\circ}$, o objetivo de "ampliar a eficiência nas contratações públicas e a competitividade entre os licitantes." (BRASIL, 2011a, on-line). Entre as principais inovações trazidas pela norma, destacam-se a contratação integrada ${ }^{3}$, a possibilidade de remuneração variável ao contratado, a inversão das fases de habilitação e julgamento, a fase única recursal e o orçamento sigiloso.

presente trabalho tratará especificamente dessa última inovação, conforme dispõe o art. $6^{\circ}$ da norma:

1 Vide art. $1^{\circ}$ da Lei n. 12462/2011 (BRASIL, 2011a). Além dos incisos de I a X, ali constantes, há remissão ao RDC por parte de outras leis, a exemplo da Lei n. 12.873/2012, que autoriza a Companhia Nacional de Abastecimento a utilizar o RDC para a contratação de todas as ações relacionadas à reforma, modernização, ampliação ou construção de unidades armazenadoras próprias destinadas às atividades de guarda e conservação de produtos agropecuários em ambiente natural.

2 "Art. $3^{\circ}$ As licitações e contratações realizadas em conformidade com o RDC deverão observar os princípios da legalidade, da impessoalidade, da moralidade, da igualdade, da publicidade, da eficiência, da probidade administrativa, da economicidade, do desenvolvimento nacional sustentável, da vinculação ao instrumento convocatório e do julgamento objetivo." (BRASIL. 2011, on-line).

3 "Art. 9ำ § 1ำ, A contratação integrada compreende a elaboração e o desenvolvimento dos projetos básico e executivo, a execução de obras e serviços de engenharia, a montagem, a realização de testes, a pré-operação e todas as demais operações necessárias e suficientes para a entrega final do objeto." (BRASIL. 2011, on-line). 
Observado o disposto no $\S 3^{\circ}$, o orçamento previamente estimado para a contratação será tornado público apenas e imediatamente após o encerramento da licitação, sem prejuízo da divulgação do detalhamento dos quantitativos e das demais informações necessárias para a elaboração das propostas. [...] $\S 3^{\circ} \mathrm{Se}$ não constar do instrumento convocatório, a informação referida no caput deste artigo possuirá caráter sigiloso e será disponibilizada estrita e permanentemente aos órgãos de controle externo e interno (BRASIL, 2011, on-line).

O artigo investigará a contribuição do orçamento sigiloso para a eficiência das licitações e das contratações públicas. Por intermédio de revisão bibliográfica, pesquisa de atos normativos e apresentação de estudos empíricos de órgãos de controle, sustenta-se, aqui, a constitucionalidade e a adequação, do ponto de vista da eficiência, da adoção do sigilo orçamentário nas licitações e nas contratações públicas. Todavia, serão feitas ressalvas em relação ao regime de contratação integrada, concluindo-se pela inadequação do uso da prática nesse caso, especialmente em razão da complexidade do objeto associada à ausência de projeto básico.

\section{CONTEXTO NORMATIVO}

A Constituição Federal de 1988 (CF/88), em seu art. 22, dispõe que compete privativamente à União legislar sobre:

XXVII - normas gerais de licitação e contratação, em todas as modalidades, para as administrações públicas diretas, autárquicas e fundacionais da União, Estados, Distrito Federal e Municípios, obedecido o disposto no art. 37, XXI, e para as empresas públicas e sociedades de economia mista, nos termos do art. $173, \S 1^{\circ}$, III (BRASIL, 1988, on-line).

A Lei n ${ }^{0}$ 8.666/93 disciplina o mencionado inciso XXI, porém, apesar da qualidade da norma para frear o patrimonialismo, o excessivo apego ao formalismo e à rigidez processual, com ênfase no controle a priori, típicos da burocracia weberiana ${ }^{4}$, acabou por distanciar as licitações e contratações públicas, no Brasil, da administração gerencial ${ }^{5}$.

A não previsão de procedimento eletrônico, a prevalência do critério de preço sobre a técnica e a habilitação de todos os licitantes anteriormente ao julgamento das propostas são alguns dos exemplos desse excesso de controle dos processos, com menor preocupação em relação aos resultados. A metodologia da Lei de Licitações é utilizada anualmente para a

4 "Foi um grande progresso o aparecimento, no século XIX, de uma administração pública burocrática em substituição às formas patrimonialistas de administrar o Estado. Weber [...] destacou com muita ênfase a superioridade da autoridade racional-legal sobre o poder patrimonialista." (PEREIRA, 1998, p. 26). Todavia, o excesso de formalismo e a ênfase nos controles a priori, ligados aos procedimentos, além da rigidez hierárquica, acabaram por tornar o modelo burocrático inadequado para administrar o Estado de Bem-estar Social.

5 Esse modelo não nega todos os princípios da burocracia, como impessoalidade e profissionalismo, mas muda o foco dos controles para os resultados, e não para os procedimentos. A estratégia se volta para uma clara definição de objetivos, com maior autonomia do administrador e cobrança de resultados, ou controle a posteriori. $\mathrm{O}$ administrador público passa a ser merecedor de confiança, ainda que limitada até certo grau. O que se pretende é reduzir os gastos públicos em curto prazo e aumentar a eficiência mediante orientação gerencial, a médio prazo (PEREIRA, 1998, p. 21-38). 
aquisição de mais de $\mathrm{R} \$ 250$ bilhões ao ano. No entanto, notam-se reclamações constantes sobre a baixa qualidade dos produtos adquiridos, os elevados custos praticados, a demora no processo de contratação e o fato de não evitar fraudes entre os concorrentes, que podem criar cartéis para a oferta de preços, a exemplo dos casos relatados na operação lava jato, em análise pelo Judiciário brasileiro.

No intuito de procurar soluções, dentro da tradicional lógica de licitações, os agentes públicos se adaptaram para produzir pregões por meio eletrônico, atas de preços, centrais de compras e várias outras soluções que têm trazido maior eficiência e economia aos cofres públicos. Foi no matiz dessa busca por mais eficiência, em um maior alinhamento à administração gerencial, que se deu a criação do RDC.

\section{O SIGILO COMO INSTRUMENTO PARA MAIOR EFICIÊNCIA ${ }^{6}$}

O sigilo dos orçamentos aqui tratado diz respeito ao orçamento estimado. A importância da elaboração dessa estimativa orçamentária não diminui em face da postergação de sua divulgação. Um dos requisitos de validade da fase externa de uma licitação consiste na existência de um orçamento estimado de custos pertinentes à futura contratação, porém a ausência dessas estimativas pode conduzir a administração a aceitar proposta defeituosa (JUSTEN FILHO, 2013, p. 105-127), ou seja, trata-se de atividade inafastável, sendo medida imprescindível para a definição do objeto licitado e dos custos atinentes a sua execução (CARDOSO, 2014, p. 82). Essa obrigação decorre, ainda, da Lei de Responsabilidade Fiscal $(\mathrm{LRF})^{7}$ e das sucessivas Leis de Diretrizes orçamentárias (LDOs) ${ }^{8}$. Em suma, existem dois

6 O conceito de eficiência utilizado no presente artigo é o proposto pelo Tribunal de Contas da União (TCU): "Relação entre os produtos (bens e serviços) gerados por uma atividade e os custos dos insumos empregados para produzi-los, em um determinado período de tempo, mantidos os padrões de qualidade. Essa dimensão se refere ao esforço do processo de transformação de insumos em produtos. Pode ser examinada sob duas perspectivas: minimização do custo total ou dos meios necessários para obter a mesma quantidade e qualidade de produto; ou otimização da combinação de insumos para maximizar o produto quando o gasto total está previamente fixado." (BRASIL, 2012a, on-line).

7 "Art. 15. Serão consideradas não autorizadas, irregulares e lesivas ao patrimônio público a geração de despesa ou assunção de obrigação que não atendam o disposto nos arts. 16 e 17. Art. 16. A criação, expansão ou aperfeiçoamento de ação governamental que acarrete aumento da despesa será acompanhado de: I - estimativa do impacto orçamentário-financeiro no exercício em que deva entrar em vigor e nos dois subsequentes; II - declaração do ordenador da despesa de que o aumento tem adequação orçamentária e financeira com a lei orçamentária anual e compatibilidade com o plano plurianual e com a lei de diretrizes orçamentárias. [...] Art. 17. Considera-se obrigatória de caráter continuado a despesa corrente derivada de lei, medida provisória ou ato administrativo normativo que fixem para o ente a obrigação legal de sua execução por um período superior a dois exercícios. $§ 10$ Os atos que criarem ou aumentarem despesa de que trata o caput deverão ser instruídos com a estimativa prevista no inciso I do art. 16 e demonstrar a origem dos recursos para seu custeio." (BRASIL, 2000, on-line).

8 "Art. 127. O custo global de obras e serviços de engenharia contratados e executados com recursos dos orçamentos da União será obtido a partir de composições de custos unitários, previstas no projeto, menores ou iguais à mediana de seus correspondentes no Sistema Nacional de Pesquisa de Custos e Índices da Construção Civil - SINAPI, mantido e divulgado, na internet, pela Caixa Econômica Federal, e, no caso de obras e ser- 
momentos distintos: o primeiro deles consiste na elaboração do orçamento estimado na fase interna da licitação e o segundo, na divulgação desse orçamento previamente elaborado (CARDOSO, 2014, p. 82). ${ }^{9}$

No âmbito da Ação Direta de Inconstitucionalidade (ADI) no 4645, o Poder Executivo Federal, por meio da Advocacia-Geral da União (AGU), afirmou que os objetivos do orçamento sigiloso são o desestímulo a conluios e a outras práticas anticoncorrenciais e a redução de preços, o que se nota a partir de estudos comparativos com práticas estrangeiras. ${ }^{10}$ Os dois pressupostos são contestáveis.

\subsection{A CONTESTAÇÃO DO PRESSUPOSTO DE DESESTÍMULO A CONLUIOS}

Sobre o primeiro ponto, diz-se que o conhecimento de antemão, pelos licitantes, dos valores orçados pela administração, sendo esses valores referenciais para suas decisões, poderia estimular um acerto ilegal entre os participantes do certame em relação a suas propostas, para a consecução dos resultados almejados pelos licitantes em conluio, distanciando o resultado do que seria a proposta mais vantajosa para a administração. Isso ocorreria em detrimento de uma disputa direta sobre o objeto do certame, que deveria ocorrer com a apresentação de preços realmente factíveis aos concorrentes, alcançados por meio de seus respectivos cálculos - mais próximos dos reais custos de oportunidade - e de seu empenho em vencer o certame (CAMMAROSANO, 2014, p. 50-55).

Este não parece ser um argumento suficiente no sentido da adoção do sigilo dos orçamentos. Primeiro, porque se considerarmos a existência de má-fé no âmbito do certame licitatório, haveria, igualmente, riscos relacionados à manutenção do segredo no orçamento. $\mathrm{O}$ orçamento poderia ser divulgado, ilicitamente, a determinado licitante por parte da administração, beneficiando-o em detrimento dos demais. Soma-se a isso a possiblidade de vazamento por parte dos órgãos de controle interno e externo, podendo um de seus inte-

viços rodoviários, à tabela do Sistema de Custos de Obras Rodoviárias - SICRO, excetuados os itens caracterizados como montagem industrial ou que não possam ser considerados como de construção civil." (BRASIL, 2010a, on-line, grifo do autor).

9 No direito internacional, o Tribunal de Justiça da União Europeia defende a existência de outros momentos de transparência, como o tempo suficiente em relação ao nível de detalhamento necessário dos relatórios de análise de desclassificação de concorrentes para o efetivo direito de recurso, por exemplo. Ver Caso C367/95 P Commission v Sytraval and Brink's France [1998] ECR I1719, e julgamento of 28 de fevereiro de 2008 no Caso C17/07 P Neirinck v Commission.

10 " $[. .$.$] a proteção do erário, assegurando que as propostas dos licitantes correspondam a um valor pelo qual$ estejam dispostos a executar a obra, sem que os preços convirjam artificialmente para patamares próximos ao orçamento anunciado, quando poderiam ser mais baixos'. Com efeito, quando os licitantes desconhecem o orçamento estimado, a tendência é que apresentem propostas mais atrativas para a administração, atendendo ao princípio da eficiência e da economicidade. Além disso, estudos internacionais demonstram que essa prática desestimula o conluio e outras condutas anticoncorrenciais, motivo pelo qual o sigilo da estimativa orçamentária é adotado em diversos países, como os Estados Unidos e as nações integrantes da União Europeia." (BRASIL, 2017a, on-line). 
grantes ser seduzido pela oportunidade de enriquecer ilicitamente (CAMMAROSANO, 2014, p. 50-55), em razão do comando do art. $6^{\circ}, \S 3^{\circ}$, da Lei do RDC: "Se não constar do instrumento convocatório, a informação referida no caput deste artigo possuirá caráter sigiloso e será disponibilizada estrita e permanentemente aos órgãos de controle externo e interno." (BRASIL, 2011a, on-line).

Todavia, caso o sigilo seja quebrado por todos ou quase todos os licitantes, por meio de vazamento, abstraindo-se dos aspectos relacionados à ilicitude da conduta e considerando apenas questões relacionadas ao valor das propostas, estar-se-ia nas mesmas condições da divulgação do orçamento em anexo do edital (ZYMLER, 2013, p. 103-105), uma vez que, nos dois casos, os licitantes teriam acesso ao orçamento estimativo.

Caso o vazamento seja direcionado a apenas um ou poucos licitantes, a tendência seria que o(s) beneficiado(s) propusessem orçamentos próximos àquele fixado pela administração, enquanto os demais apresentariam propostas que entendessem competitivas (sem conhecimento do orçamento). Decorreriam, então, duas possíveis situações: na primeira, algum dos outros licitantes apresenta proposta inferior ao orçamento estimado pela administração e a empresa beneficiada pelo vazamento não seria a vencedora do certame; na segunda, a vencedora do certame é aquela mesma empresa beneficiária do vazamento, o que afrontaria o princípio da isonomia (ZYMLER, 2013, p. 103-105). Para a ocorrência do segundo caso, seria necessário que o potencial teórico do sigilo do orçamento, nos moldes que serão aqui explanados ${ }^{11}$, não se realizasse no caso concreto.

Logo, o problema do vazamento seletivo não tem a capacidade em si de afastar o sucesso dos melhores contratantes, uma vez que, se os benefícios teóricos da adoção do sigilo orçamentário se verificarem, a vitória no certame não terá relação com o conhecimento acerca do orçamento estimado. Essa conclusão está em linha com o modelo de valor comum, que, na teoria dos leilões, é caracterizado por um objeto cujo preço deriva de um valor de mercado, conhecido de todos, que baliza os valores ofertados, todavia esses valores se diferenciam em razão de estudos próprios de cada licitante a respeito do objeto licitado (SILVA, 2011, p. 12). Já o vazamento, digamos, generalizado, igualaria as condições do certame ao modelo de orçamento estimado divulgado como anexo do edital e, portanto, não apresentaria desvantagem em relação ao orçamento aberto.

Depreende-se do exposto que, levando-se em consideração todos os aspectos inerentes ao sigilo ou à divulgação do orçamento, há mais vantagens relacionadas à adoção do primeiro. Da mesma forma, no Direito Europeu, tal como construído pelo Tribunal de Justiça da União Europeia, considera-se que o excesso de transparência pode acarretar prejuízos para a licitude da licitação (SANCHEZ-GRAELLS, 2013, p. 13).

Em suma, o risco de práticas ilícitas tanto relacionadas à divulgação do orçamento (sem sigilo) - quando os licitantes combinariam preços próximos aos estimados pela administra-

11 O potencial teórico do sigilo orçamentário será explicado na sequência. A referência, aqui, é a uma tendência a melhores propostas. 
ção - quanto relacionadas a sua divulgação postergada (sigilo) - quando haveria ricos de vazamento a um só licitante -, tornam extremamente frágil o dito potencial do orçamento sigiloso em combater conluios. Apesar disso, os riscos associados à manutenção do sigilo mostram-se menos prejudiciais ao Poder Público, uma vez que o conluio, nesse caso, tem menor potencial prejudicial, em termos de vantagem das propostas.

\subsection{A CONFIRMAÇÃO DO PRESSUPOSTO DA REDUÇÃO DE PREÇOS}

A respeito do segundo ponto (potencial redução dos preços ocasionada pela utilização do sigilo orçamentário), a não divulgação do orçamento objetiva evitar que as propostas gravitem em torno do orçamento estimado previamente conhecido, uma vez que, sem as balizas das propostas dos outros licitantes e sem o conhecimento do orçamento estimado, estimula-se o licitante a "oferecer um preço realmente competitivo e dentro do limite de sua capacidade de executar a avença com uma lucratividade adequada.” (ZYMLER, 2013. p. 103-105).

A teoria econômica reconhece que as licitações apresentam estrutura que se aproxima de um leilão, no qual, teoricamente, o grau de informações disponibilizado por uma das partes influirá no comportamento da outra. Existem, essencialmente, quatro tipos de leilões definidos pela literatura econômica, quais sejam, leilão de primeiro preço, leilão de segundo preço, leilão inglês e leilão holandês (SILVA, 2011, p. 8-11).

Os dois últimos são leilões abertos, nos quais há dinâmica de lances (à semelhança do pregão, em sua fase de lances), porém, no leilão inglês, o preço começa alto e vai sendo reduzido - com desistência sequencial dos participantes - até que reste apenas um disposto a contratar pelo preço mais baixo. O leilão holandês se dá de modo inverso, sendo o preço inicialmente oferecido extremamente reduzido. Esse preço vai aumentando, e, quando o primeiro licitante o aceitar, encerra-se o leilão (SILVA, 2011, p. 8-11).

Nos leilões de primeiro e segundo preço, as propostas são apresentadas em envelopes lacrados, de tipo selado ou fechado. Em ambos, o vencedor do certame é aquele que apresentar a menor proposta. No de primeiro preço, o valor contratado obedecerá à proposta do licitante vencedor, que corresponde ao menor preço. No de segundo preço, o valor corresponderá ao segundo menor lance, apresentado pelo licitante perdedor de menor lance (SILVA, 2011, p. 8-11).

O tipo relevante, para o escopo do presente artigo, é o leilão de primeiro preço com preço de reserva - que corresponde ao valor máximo que a administração aceitaria pagar pelo objeto licitado - sigiloso, ou não divulgado a priori. Tal estrutura se assemelha a uma licitação nos moldes da legislação brasileira, com utilização do orçamento sigiloso.

A ciência econômica demonstra que a não divulgação do orçamento estimado pela administração resulta em incentivo a comportamentos competitivos, conduzindo potencialmente a propostas mais vantajosas derivadas da intensificação da disputa. Isso ocorre em razão da influência no comportamento dos licitantes ocasionada pela supressão de informações, visando a propostas mais reduzidas (CARDOSO, 2014, p. 94-96). 
A divulgação do preço de reserva da administração - o orçamento estimativo - incentivaria a apresentação de propostas mais próximas desse valor, comportamento tanto mais provável quanto menor for o número de licitantes concorrentes. ${ }^{12} \mathrm{~A}$ ausência de certeza a respeito do valor do orçamento estimado pela administração, portanto, seria um incentivo mais efetivo para os licitantes reduzirem seus preços (CARDOSO, 2014, p. 94-96).

Os argumentos apresentados no segundo ponto parecem alinhados ao princípio da eficiência e contam com alguma comprovação empírica. Brisset e Naegelen concluíram, em estudo publicado em 2006, abordando um leilão inglês com valores privados e independentes, que a utilização de preço de reserva secreto em leilões governamentais pode trazer ótimos resultados, uma vez que, no modelo proposto pelos autores, a capacidade de comprometimento com o preço de reserva, especialmente alta para o Poder Público, é fator essencial para o bom resultado do sigilo do preço - com alguma aversão constante relativa ao risco por parte dos participantes (BRISSET; NAEGELEN, 2006). Uma conclusão similar foi obtida por Rosenkranz e Schimitz em que, utilizando a reference-based utility, função aplicada às ciências comportamentais, foram identificadas vantagens no uso do sigilo dos preços de reserva para leilões de primeiro e segundo preços (ROSENKRANZ; SCHMITZ, 2007).

Por fim, em um estudo que utilizou modelo denominado distribuição de malha, verificou-se que há correlação entre a magnitude do preço de referência adotado pelo Poder Público e a obtenção de maiores descontos quando adotado o orçamento sigiloso. Essa correlação é positiva, ou seja, quanto maior for o preço de referência, maior a possibilidade de redução dos custos para Governo na contratação. Isso seria decorrente do maior desconhecimento do mercado por parte da administração, quando comparada aos licitantes, e do temor de licitações desertas ou fracassadas (SILVA, 2011, p. 37).

Apesar da mencionada correlação positiva entre preço de referência e redução de custos, o que, à primeira vista, poderia ir de encontro às conclusões do presente trabalho, o autor não considerou as complicações decorrentes do uso do sigilo em conjunto com contração integrada. O caso do Fundo Nacional de Desenvolvimento da Educação (FNDE), constante do capítulo seguinte, corrobora essas conclusões.

\section{O SIGILO COMO INSTRUMENTO PARA MAIOR EFICIÊNCIA ANTES DO RDC}

O sigilo já era utilizado há alguns anos por empresas públicas. A Petrobrás, por exemplo, realizava licitações com base no Decreto $2.745 / 98^{13}$, que não trazia previsão de divulgação

12 Lógica similar existe no sistema de compras públicas europeu, embora, por vezes, sua efetividade dependa da capacidade de dedução dos valores orçados pelos próprios proponentes, a luz dos relatórios apresentados pela administração. Ver, por exemplo: Caso T-474/10 Evropaïki Dynamiki v Commission (DIGIT). Julgamento de 15 de outubro de 2013. Caso T-668/11 VIP Car Solutions v Parliament II, julgamento de 6 de junho de 2013.

13 Com o advento da Lei $n^{\circ} 13.303 / 2016$, o Decreto $n^{\circ} 2.745 / 98$ perde seu fundamento de validade, uma vez que o art. 67 da Lei $n^{\circ}$ 9.478/97 foi revogado expressamente. 
antecipada do orçamento estimado. A empresa utilizava, portanto, o sigilo orçamentário. ${ }^{14} \mathrm{O}$ Tribunal de Contas da União (TCU) apreciou a matéria no Acórdão do TCU n ${ }^{0}$ 2.528/2012 - Plenário, que trata de licitação realizada na modalidade convite, nos moldes do aludido decreto. No caso, a Petrobras manteve oculta a planilha orçamentária e apresentou a sua estimativa de preços apenas no momento da abertura das propostas. No julgado, o Ministro-Substituto André de Carvalho, além de asseverar que o emprego de planilha oculta se mostra afinado com a lógica econômica de mercado, afirma que tal fato não constituiu, por si só, irregularidade insanável, sendo a medida, inclusive, estimulada no âmbito das licitações conduzidas com base no RDC. De acordo com o Ministro, "observa-se claramente que a adoção da aludida planilha oculta não se mostra, por si só, indevida ou desarrazoada, ainda mais agora que conta, mesmo que por analogia, com certo respaldo legal" (BRASIL, 2012b, on-line), se referindo, aqui, à positivação do sigilo dos orçamentos pelo RDC.

Esse entendimento similar é aplicado ao caso do Pregão. No Acórdão do TCU n ${ }^{0}$ 2080/2012 - Plenário, o Ministro José Jorge afirmou que é firme o entendimento do TCU de que a administração não está obrigada a anexar ao edital o orçamento de referência da licitação e de que seria necessário apenas constar o documento do respectivo procedimento administrativo, conforme interpretação da Lei n ${ }^{0}$ 10.520/2002.15

Nessa mesma decisão, afirma José Jorge que, embora a ampla publicidade seja imperativa na administração Pública, no caso tratado, de diferimento da publicação das informações do orçamento estimativo, o acesso ao orçamento colidiria com outros princípios não menos importantes, como o da busca da proposta mais vantajosa para a administração e, consequentemente, a reserva do seu conteúdo não viola o princípio da publicidade, nem mesmo o seu propósito de assegurar o controle pela sociedade da legalidade e da legitimidade dos atos administrativos (BRASIL, 2012c).

O relatório da decisão ora comentada traz uma justificativa pela qual, nesse caso, o acesso ao orçamento colidiria com a busca pela proposta mais vantajosa. Trata-se de verificação empírica da eficiência da utilização do sigilo dos orçamentos. Conforme informações apresentadas pelo FNDE, em síntese de resultados de licitações realizadas por meio de pregão com sistema de registro de preços, a não divulgação do orçamento estimado na fase interna (ou melhor, sua postergação) acabou por gerar descontos significativos em relação ao valor estimado (BRASIL, 2012c).

14 O TCU considerou o Decreto inconstitucional, por razões formais, embora tenha aprovado a lógica utilizada pela Petrobrás: "Ora, tendo em vista que a norma contida no art. 173, § $1^{\circ}$, inciso III, da Constituição Federal, é de eficácia limitada, e não tendo sido editado até o momento o estatuto jurídico previsto naquele dispositivo, está correto o entendimento de que não há como afastar a única lei que tratou do tema licitações, qual seja, a Lei no 8.666/1993, que permanece aplicável tanto à Administração Direta quanto à Indireta". (BRASIL, 2010b, on-line).

15 "dos autos do procedimento constarão [...] o orçamento, elaborado pelo órgão ou entidade promotora da licitação, dos bens ou serviços a serem licitados.” (BRASIL, 2012c, on-line). 
Tabela 1 - Orçamento Sigiloso no FNDE

\begin{tabular}{l|l|l|l|l}
\hline $\begin{array}{l}\text { No/ano do } \\
\text { Edital }\end{array}$ & Objeto da licitação & $\begin{array}{l}\text { Valor total esti- } \\
\text { mado pela admi- } \\
\text { nistração }\end{array}$ & $\begin{array}{l}\text { Valor total } \\
\text { da proposta } \\
\text { vencedora }\end{array}$ & $\begin{array}{l}\text { Desconto } \\
\text { obtido }\end{array}$ \\
\hline $10 / 12$ & Aquisição de ônibus escolar acessível & $191.683 .736,00$ & $105.600 .000,00$ & $45 \%$ \\
\hline $32 / 2011$ & $\begin{array}{l}\text { Aquisição de equipamentos para UTI } \\
\text { e centro cirúrgico para os hospitais } \\
\text { universitários }\end{array}$ & $107.487 .398,65$ & $48.213 .590,00$ & $55 \%$ \\
\hline $81 / 2011$ & Aquisição de tablets educacionais & $522.823 .500,00$ & $333.118 .500,00$ & $36 \%$ \\
\hline $18 / 2011$ & Aquisição de ônibus escolar rural & $1.019 .193 .794,17$ & $818.028 .400,00$ & $20 \%$ \\
\hline
\end{tabular}

Fonte: Relatório do Acórdão 2528/2012 - Plenário do TCU (BRASIL, 2012b, on-line).

No entendimento do TCU, com o qual concordamos, a manutenção do sigilo orçamentário, até momento posterior à fase de lances, não é capaz de macular o certame, na medida em que contribuiu para que o FNDE obtivesse economia significativa em licitações anteriores. ${ }^{16}$

Esse entendimento do TCU não é pacífico na doutrina. Nesse sentido, Marçal Justen Filho entende que a publicidade deve ser sempre prestigiada, ressalvados os casos legalmente autorizados, portanto discorda da interpretação prevalente no TCU relativa ao sigilo do valor do orçamento no âmbito do pregão, uma vez que a Lei do Pregão não o autoriza (JUSTEN FILHO, 2013, p. 105-127).${ }^{17}$ Apesar disso, a tese parece pacificada no âmbito do TCU.

\section{O SIGILO NO RDC: A PREVALÊNCIA DO PRINCÍPIO DA EFICIÊNCIA SOBRE O DA PUBLICIDADE}

O diferimento da publicação das informações do orçamento estimativo é alvo de questionamentos relacionados à mitigação do princípio da publicidade. ${ }^{18}$ Diz-se que o fato de não existir, no Pregão, obrigação de incluir no instrumento convocatório o orçamento estimativo detalhado em planilha de custos unitários não autoriza a Administração Pública a negar acesso a esses documentos quando instada a fazê-lo. Para essa corrente, qualquer licitante ou interessado poderia requerer e deveria obter vista do processo administrativo licitatório, sendo permitido, inclusive, obter cópia dos orçamentos estimativos, a qualquer tempo, após a publicação do edital. Seguindo por essa linha, a norma do art. $6^{\circ}$ da Lei $\mathrm{n}^{\circ} 12.462 / 11$ seria inconstitucional, pois determina

16 Tabela retirada do relatório do Acórdão nº. 2528/2012. Plenário (BRASIL, 2012c).

17 Ressalta-se que, no pregão, diferentemente do caso do RDC, o sigilo orçamentário não conta com expressa previsão legal.

18 "O princípio da publicidade nada mais é que a divulgação, tendo como finalidade o conhecimento público. [...] tem como base o fato de que o administrador exerce função pública, atividade em nome e interesse do povo, por isso, nada mais justo que o titular desse interesse tenha ciência do que está sendo feito com seus direitos." (MARINELA, 2013, p. 353). 
o sigilo absoluto em relação aos orçamentos estimativos até a homologação, porém a única interpretação possível é a de que, mesmo que não sejam publicados como parte integrante do instrumento convocatório, os orçamentos estimativos "devem estar disponíveis e acessíveis a qualquer interessado, inclusive para cópias, a partir da publicação do edital." (FERREIRA; SANTOS, 2012, p. 171-183).

No presente trabalho, discorda-se dessa tese, em primeiro lugar, porque a determinação de sigilo em relação aos orçamentos foi mitigada pela jurisprudência do TCU que, no Acórdão nº 306/2013 - Plenário afirmou que orçamento sigiloso, apesar do comando imperativo da norma, "é uma possibilidade, talvez uma preferência, mas não uma meta compulsória" (BRASIL, 2013, on-line) e, diante de múltiplas possibilidades, "basta motivar o caminho de maior conveniência, dentro dos novos regramentos e dos ideais de eficiência, eficácia, efetividade e economicidade.” (BRASIL, 2013, on-line).

Em segundo lugar, porque os princípios são mandatos de otimização, devendo respeitar as possibilidades legais e fáticas, que não obedecem, como se dá com as regras, à regra de "tudo ou nada", sendo passíveis, portanto, de ponderação. Isso significa que, quando ocorre colisão, um dos princípios terá de ceder, sem, contudo, ser declarado inválido (ALEXY, 2001, p. 112), e é exatamente isso que ocorre nesse caso. Se o intuito é ampliar a competitividade e atingir uma redução dos custos envolvidos, não haverá inconstitucionalidade em postergar a divulgação do orçamento para momento posterior ao certame licitatório, tendo em vista a relativização do princípio da publicidade em decorrência do princípio da eficiência. Os objetivos do princípio da publicidade ${ }^{19}$ serão atendidos, e o controle social permanecerá hígido, pois poderá ser exercido por qualquer cidadão quando da divulgação do orçamento, uma vez que a não divulgação é apenas temporária, ou a qualquer momento, pelos órgãos de fiscalização (TREUTEL, 2014, p. 121-132).

Ademais, como afirmado no tópico 3, o TCU já se posicionou favoravelmente a esse entendimento. Analisando o caso do Pregão, o órgão assentou que o acesso ao orçamento colidiria com outros princípios, como o da busca da proposta mais vantajosa para a administração, não configurando violação ao princípio da publicidade (BRASIL, 2012c). Por fim, até mesmo, Marçal Justen Filho, que, como dito anteriormente, é contrário ao sigilo dos orçamentos no caso do Pregão, por ausência de previsão expressa, admite a prática como regular no caso do $\mathrm{RDC}^{20}$

19 “[...] o princípio da publicidade, que tem como objetivos precípuos, no caso das licitações públicas, (i) a participação do maior número de interessados, (ii) a proteção à igualdade entre os licitantes e (iii) viabilizar o amplo controle da atividade administrativa na licitação e do contrato dela decorrente. De outro, (a) a busca da maior competição entre os licitantes, tendo como consequência (b) a redução da possibilidade de conluio entre eles na participação em licitações e (c) a obtenção de propostas mais vantajosas." (CARDOSO, 2014, p. 82).

20 "[...] a restrição da publicidade do ato administrativo depende de previsão legislativa [...] no caso específico, a Lei do RDC expressamente consagrou a previsão do sigilo." (JUSTEN FILHO, 2013, p. 105-127). 


\section{O INÍCIO DA FASE DE NEGOCIAÇÃO COMO MOMENTO IDEAL PARA A REVELAÇÃO DO ORÇAMENTO ESTIMADO}

A Lei n ${ }^{0}$ 12.462/2011 (BRASIL, 2011a, on-line), em seu art. 60, estabelece que: "o orçamento previamente estimado para a contratação será tornado público apenas e imediatamente após o encerramento da licitação.” Esse comando contraria o disposto no Decreto $n^{0} 7.581 / 2011$, que assim dispõe, em seu art. 9': "O orçamento previamente estimado para a contratação será tornado público apenas e imediatamente após a adjudicação do objeto.” (BRASIL, 2011b, on-line). Essa contradição ocorre porque o "encerramento da licitação", tomando como base a própria Lei do RDC, seria antes da adjudicação do objeto e da homologação pela autoridade superior, tendo em vista o que diz o art. 28: "Exauridos os recursos administrativos, o procedimento licitatório será encerrado" (BRASIL, 2011a, on-line), conjugado com o art. 27: "Salvo no caso de inversão de fases, o procedimento licitatório terá uma fase recursal única, que se seguirá à habilitação do vencedor." (BRASIL, 2011a, on-line).

Em face dessa contradição, deveria prevalecer a Lei, porém o que, de fato, ocorre é a divulgação do orçamento estimado, somente após a fase recursal, e isso terminaria possibilitando a desclassificação de propostas de licitantes por valores superiores ao orçamento estimativo sem que a eles seja dado o conhecimento do conteúdo desse orçamento para que possam recorrer, ou seja, ficariam prejudicados o contraditório e a ampla defesa em uma mitigação desarrazoada do princípio da publicidade, em confronto com a CF/88 (CAMMAROSANO, 2014, p. 50-55), uma vez que recorreriam em face de algo que não conhecem.

A razão para a postergação da divulgação do orçamento estimado é justamente fomentar a disputa entre os licitantes, influenciando seu comportamento, como anteriormente explicado. Ao término da fase de lances, por estar encerrada a disputa, não há mais sentido em manter o sigilo do orçamento (CARDOSO, 2014, p. 110). Sobre essa questão, a solução pertinente é a divulgação do orçamento antes do início da fase de negociação, uma vez que resolve o problema do contraditório e da ampla defesa, dando conhecimento aos licitantes do orçamento estimado antes da fase recursal, e permite uma negociação mais racional com o vencedor ou com os demais classificados.

Tal entendimento foi sedimentado no Acórdão do TCU no 306/2013 - Plenário, em trecho já citado aqui, quando afirma que, após uma aprofundada interpretação da Lei do RDC, o orçamento sigiloso seria uma possibilidade, até uma preferência, mas não uma meta compulsória. Diante disso, bastaria motivar o caminho a ser tomado em cada caso, respeitando-se os ideais de eficiência, eficácia, efetividade e economicidade dentro dos limites dos novos regramentos. A partir desse entendimento, não obstante o Decreto 7.581/2011 regulamentar que somente ao fim do certame é que deve o orçamento ser publicado (a Lei estabelece a adjudicação como condição), para fazer valer a real possibilidade de negociar, desde que em ato público e devidamente justificado, não haveria, "em princípio, reprovabilidade em abrir o sigilo na fase de negociação.” (BRASIL, 2013, on-line). 
Tal tese, de certa forma, foi encampada pelo Decreto $\mathrm{n}^{\mathrm{o}} 8.080 / 2013$, que deu nova redação ao $\S 3^{\circ}$ do art. 43 do Decreto $n^{\circ} 7.581 / 2011$ :

Após o encerramento da fase de apresentação de propostas, a comissão de licitação classificará as propostas por ordem decrescente de vantajosidade. $\S 1^{\circ}$ Quando a proposta do primeiro classificado estiver acima do orçamento estimado, a comissão de licitação poderá negociar com o licitante condições mais vantajosas. $\S 2^{\circ}$ A negociação de que trata o $\S 1$ o poderá ser feita com os demais licitantes, segundo a ordem de classificação, quando o primeiro colocado, após a negociação, for desclassificado por sua proposta permanecer superior ao orçamento estimado. $\S 3^{\circ}$ Encerrada a etapa competitiva do processo, poderão ser divulgados os custos dos itens ou das etapas do orçamento estimado que estiverem abaixo dos custos ou das etapas ofertados pelo licitante da melhor proposta, para fins de reelaboração da planilha com os valores adequados ao lance vencedor, na forma prevista no art. 40, $\S 2^{\circ}$ (BRASIL, 2011b, on-line).

Todavia, a nova redação não atende plenamente ao ideal assentado na decisão do TCU, pois a divulgação apenas dos valores que estiverem abaixo dos custos ou das etapas ofertados pelos licitantes não possibilita a ampla contestação, por parte de todos os participantes, das metodologias e dos cálculos realizados pela administração no que diz respeito ao orçamento estimado. A redação do decreto, de certa forma, resolve a questão da negociação mais racional com o licitante vencedor em relação aos itens que ainda permanecerem acima do orçamento estimado, mas, no que se refere ao contraditório, à ampla defesa e à contestação dos métodos utilizados pelo Poder Público para realizar as estimativas, o problema persiste. Apenas uma divulgação total das estimativas resolveria o problema, o que não decorre da nova redação do $§ 3^{\circ}$ do art. 43 do Decreto n ${ }^{\mathrm{o}} 7.581 / 2011$.

\section{A EFICIÊNCIA DO SIGILO COM EXCEÇÃO PARA O REGIME DE CON- TRATAÇÃO INTEGRADA}

O Ministério da Transparência e Controladoria-Geral da União (CGU) realizou estudo em que foram analisados 155 editais que utilizaram o RDC e constatou que a maioria dos editais $(96,1 \%)$ de RDC publicados pela Sede do Departamento Nacional de Infraestrutura de Transportes (DNIT) tiveram preços ocultos, ou seja, apenas 6 valores de referência foram publicados (dos 155 totais). O estudo mostra que o desconto médio obtido nas licitações realizadas sem sigilo foi maior que nos casos de orçamento sigiloso. Essa análise mostra, também, que o número médio de licitantes foi maior quando não houve sigilo dos orçamentos, com a seguinte conclusão: "Em relação ao sigilo do preço de referência, não há evidências, na amostra, que ele incentive a concorrência." (BRASIL, 2017b, p. 104).

Tabela 2 - Concorrência e desconto orçamento sigiloso x público

\begin{tabular}{c|c|c}
\hline & Sem Sigilo & Com Sigilo \\
\hline Número Médio de Licitantes & 6.00 & 4.88 \\
\hline Desconto \% Médio & $14,34 \%$ & $7.30 \%$ \\
\hline
\end{tabular}

Fonte: Relatório do Auditoria OS 201505075 - CGU (BRASIL, 2017b, p. 88). 
Na sequência, diz-se que, na amostra analisada, metade das obras (24 de 48), no regime de contratação integrada, tiveram descontos inferiores a 1\%, mesmo com o sigilo para a imensa maioria dessas obras. Nessa linha, a CGU concluiu que os preços contratados ficaram, em geral, próximos ao valor de referência da licitação, conforme indicado pela dispersão dos dados, ao contrário do coletado na literatura (BRASIL, 2017b). O relatório segue com as seguintes observações:

Assim, não há evidências, na amostra, que o sigilo dificulte a prática do conluio e, por consequência, incentive a concorrência. Poder-se-ia até afirmar o contrário, visto que, nas licitações que tiveram os preços de referência divulgados, houve maior número de participantes e foram observados maiores descontos. Em verdade, as propostas vencedoras orbitaram em torno do valor de referência da licitação (BRASIL, 2017b, p. 89).

Além disso, apresenta um memorando do controle interno do DNIT:

Memorando no 166/2016 - COPORT/CGOB/DAQ/DNIT, 29/8/2016: Em relação ao Orçamento Sigiloso Referencial na modalidade RDCI das IP4 houveram [sic] descontos consideráveis em algumas Propostas Vencedoras o que gerou economia financeira para a Administração Pública, mas hoje sabemos que o Orçamento Referencial não sigiloso além de atrair um maior número de Empresas a participarem dos Certames Licitatórios também evita erros nas propostas vencedoras com a diminuição do número de aditamentos de prazo e valor dos CONTRATOS (BRASIL, 2017b, p. 89).

Passando agora à análise desse estudo, inicialmente, é forçoso dizer que o quadro inicial, que compara 6 obras com orçamentos não sigilosos com outras 149, em que foi utilizado o orçamento sigiloso, não serve para generalizações, tendo em vista o tamanho extremamente reduzido da amostra de orçamentos abertos em comparação com os sigilosos, como diz o próprio relatório: "o universo de obras de RDC que não utilizaram o instituto do sigilo é reduzido para formação de opinião definitiva." (BRASIL, 2017b, p. 104). Ademais, essa constatação vai de encontro a estudo realizado pelo TCU (BRASIL, 2017c) no mesmo DNIT, que mostra maior desconto e maior número de licitantes quando usado o orçamento sigiloso (a não ser no caso de contratação integrada):

Tabela 3 - Descontos médios x sigilo orçamentário

\begin{tabular}{c|c|c|c|c|c}
\hline $\begin{array}{c}\text { Modalidade } \\
\text { licitatória }\end{array}$ & $\begin{array}{c}\text { Modo de dis- } \\
\text { puta }\end{array}$ & $\begin{array}{c}\text { Desconto mé- } \\
\text { dio na licitação }\end{array}$ & Desvio padrão & $\begin{array}{c}\text { Número de } \\
\text { licitações }\end{array}$ & $\begin{array}{c}\text { Número Médio } \\
\text { de licitantes } \\
\text { por certame }\end{array}$ \\
\hline $\begin{array}{c}\text { RDC-Parte } \\
\text { Geral }\end{array}$ & Sigiloso & $10,84 \%$ & $7,58 \%$ & 55 & 6,96 \\
\hline $\begin{array}{c}\text { RDC-Parte } \\
\text { Geral }\end{array}$ & Não sigiloso & $4,62 \%$ & $6,66 \%$ & 19 & 6,05 \\
\hline
\end{tabular}

Fonte: Relatório do Acórdão 306/2017 - Plenário do TCU (BRASIL, 2017c, p. 18). 
Quanto à conclusão (da CGU) de que "os dados indicaram que o sigilo não deixou de induzir as propostas, visto que os preços contratados orbitaram em torno do orçamento de referência da licitação" (BRASIL, 2017b, p. 104), cabe a ressalva de que, no caso de obras rodoviárias (âmbito da amostra do DNIT), embora o valor global estimado não seja público, os preços unitários são obtidos a partir de simples consulta ao Sistema de Custos de Obras Rodoviárias (Sicro), em uma clara mitigação dos benefícios do sigilo orçamentário, o que tende a aproximar as propostas do orçamento estimado. Já em relação à afirmação de que "não há evidências, na amostra, que o sigilo dificulte a prática do conluio e, por consequência, incentive a concorrência. Poder-se-ia até afirmar o contrário [...]" (BRASIL, 2017b, p. 89), valem os argumentos apresentados no capítulo 1, que defendem a fragilidade de se utilizar a mitigação ou favorecimento dos conluios como ponto favorável ou contrário à adoção do sigilo orçamentário, tendo em vista que práticas ilícitas podem ocorrer em qualquer caso, com certa mitigação dos prejuízos quando adotado o sigilo do orçamento estimado.

Como já dito, o estudo realizado pelo TCU apontou que o sigilo dos orçamentos amplia a competitividade e reduz os preços, a não ser no caso de contratação integrada, como se vê no quadro abaixo:

Tabela 4 - Descontos médios x sigilo orçamentário (ampliada)

\begin{tabular}{l|l|l|l|l|l}
\hline Modalidade licitatória & $\begin{array}{l}\text { Modo de } \\
\text { disputa }\end{array}$ & $\begin{array}{l}\text { Desconto mé- } \\
\text { dio na licitação }\end{array}$ & $\begin{array}{l}\text { Desvio } \\
\text { padrão }\end{array}$ & $\begin{array}{l}\text { Número de } \\
\text { licitações }\end{array}$ & $\begin{array}{l}\text { Número Médio de li- } \\
\text { citantes por certame }\end{array}$ \\
\hline RDC-Contratação Integrada & Sigiloso & $4,61 \%$ & $5,84 \%$ & 41 & 5,07 \\
\hline RDC-Parte Geral & Sigiloso & $10,84 \%$ & $7,58 \%$ & 55 & 6,96 \\
\hline RDC-Contratação Integrada & $\begin{array}{l}\text { Não Sigi- } \\
\text { loso }\end{array}$ & $3,62 \%$ & $5,77 \%$ & 9 & 8,44 \\
\hline RDC-Parte Geral & $\begin{array}{l}\text { Não Sigi- } \\
\text { loso }\end{array}$ & $4,62 \%$ & $6,66 \%$ & 19 & 6,05 \\
\hline
\end{tabular}

Fonte: Relatório do Acórdão 306/2017 - Plenário do TCU (BRASIL, 2017c, p. 18).

Note-se que essa conclusão vai ao encontro do já apresentado levantamento no FNDE, sugerindo que o sigilo dos orçamentos é vantajoso em relação a objetos menos complexos ${ }^{21}$ (no caso do FNDE, a modalidade utilizada é o Pregão, que serve para compra de bens e serviços comuns, naturalmente menos complexos).

Nos casos de contratação integrada, há desvios padrão relativamente altos $(5,84 \%$ e $5,77 \%)$ e médias muito próximas (4,61\% e 3,62\%), o que não permite conclusão pela vantagem do sigilo orçamentário (BRASIL, 2017c).

Isso se deve, entre outros fatores, à ocorrência de maiores incertezas nesses certames em razão da conjugação do impedimento de acesso ao orçamento e da carência de elementos no anteprojeto que possam melhor abalizar as empresas nos seus processos decisórios anteriores à licitação. Os exemplos desse segundo ponto são: insuficiência de elementos geológicos e

21 Considerando que a Contratação Integrada seja utilizada para objetos mais complexos. 
geotécnicos para caracterizar o terreno, ausência de estudos de localização e disponibilidade de jazidas de materiais e desatualização de estudo de tráfego (BRASIL, 2017c).

A conjugação da ausência de projeto básico com orçamento sigiloso acaba por embutir um maior risco a ser assumido pelo contratado, o que gera propostas superiores aos preços de referência. Isso decorre da maior fragilidade para a obtenção de custos, características típicas dos processos de RDC - Contratação Integrada - Orçamento Sigiloso, que geram menores descontos e menor número de licitantes. Tal fato é demonstrado na tabela abaixo:

Tabela 5 - Orçamento Sigiloso - Primeira proposta x Regime licitatório

\begin{tabular}{c|c|c|c}
\hline Modalidade licitatória & $\begin{array}{c}\text { Primeira proposta da licitante } \\
\text { vencedora maior que o preço } \\
\text { de referência }\end{array}$ & $\begin{array}{c}\text { Primeira proposta da licitante } \\
\text { vencedora menor que o preço } \\
\text { de referência }\end{array}$ & $\begin{array}{c}\text { Número de } \\
\text { licitações }\end{array}$ \\
\hline $\begin{array}{c}\text { RDC-Contratação In- } \\
\text { tegrada }\end{array}$ & $69 \%$ & $31 \%$ & 36 \\
\hline RDC-Parte Geral & $25 \%$ & $75 \%$ & 52 \\
\hline
\end{tabular}

Fonte: Relatório do Acórdão 306/2017 - Plenário do TCU (BRASIL, 2017c, p. 19).

Diferente é o caso do RDC - Parte Geral (quando não se considera a Contratação Integrada), sobre o qual se conclui que orçamento sigiloso tende a ser mais eficiente na obtenção de melhores descontos para a administração nessas licitações (BRASIL, 2017c).

A conclusão do cotejo entre esses dois estudos, levando-se em consideração os dados do FNDE, citados acima, é que o orçamento sigiloso é benéfico e contribui para a eficiência, gerando descontos maiores, com ampliação da competitividade. Porém, no caso de obras de grande vulto e complexidade, quando utilizado o regime de execução contratação integrada, com milhares de itens de serviço, dois fatores acabam mitigando os benefícios: o tempo necessário para que as licitantes elaborem suas propostas de preços e os custos envolvidos nessa elaboração (BAETA, 2013, p. 162), o que ocorre em virtude da conjugação da falta de projeto básico com a não divulgação do orçamento estimado.

\section{CONCLUSÃO}

O presente trabalho buscou demonstrar a contribuição do sigilo do orçamento estimado para a eficiência das licitações e das contratações públicas, por intermédio de revisão bibliográfica, pesquisa de atos normativos e apresentação de estudos empíricos de órgãos de controle.

A teoria econômica demonstra que a incerteza gerada pela não divulgação do orçamento, em conjunto com o desconhecimento em relação às propostas dos outros licitantes, tende a gerar propostas mais vantajosas para a administração. Em relação ao potencial desestímulo a conluios, entende-se aqui que não deve ser considerado um motivo para a utilização do orçamento sigiloso diante das fragilidades dessa tese. $\mathrm{O}$ argumento é que o conhecimento do orçamento estimado potencializa a possibilidade de acerto ilegal entre os licitantes para 
apresentar preços próximos ao orçamento da administração. A tese fica enfraquecida ante a possibilidade da ocorrência de práticas ilegais também quando adotado o orçamento sigiloso, como um possível vazamento de informações.

O sigilo orçamentário, apesar de positivado no RDC, já era utilizado no âmbito do Decreto n ${ }^{0}$ 2.745/98 e do Pregão. A jurisprudência do TCU entende pela possibilidade da utilização dessa prática em ambos os casos, inclusive citando benefícios econômicos de sua utilização pelo FNDE.

O diferimento da divulgação do orçamento estimado é constitucional, uma vez que é fruto de harmonização dos princípios da publicidade com o princípio da eficiência. Nesse caso, como os controles permanecem possíveis - em um primeiro momento, por parte dos órgãos de controle e posteriormente por qualquer cidadão - e a eficiência decorre da manutenção do sigilo, não há inconstitucionalidade.

Quanto ao momento de divulgação do orçamento sigiloso, a Lei do RDC e seu decreto regulamentador padecem de problemas, sendo que a revelação deve ocorrer antes da fase de negociação.

Por fim, a partir da análise dos estudos empíricos da CGU e do TCU, foi possível concluir que a adoção de orçamentos sigilosos conduz a descontos maiores do que orçamentos não sigilosos, corroborando a teoria apresentada no que diz respeito aos leilões. Todavia, sua utilização é problemática especialmente no caso da contratação integrada, perante a conjugação de alguns fatores, quais sejam, maiores fragilidades para a obtenção de custos de construção, maiores riscos assumidos pelos licitantes, pouco tempo para a elaboração de propostas e custos para a elaboração de uma proposta que não se sabe se será vencedora. Tal situação fica agravada pela soma da ausência de projeto básico com o sigilo orçamentário na contratação de objetos complexos, com milhares de itens.

\section{REFERÊNCIAS}

ALEXY, Robert. Teoria de los Derechos Fundamentales. Madri: Centro de Estúdios Políticos y Constitucionales, 2001.

BAETA, André Pachioni. Regime Diferenciado de Contratações Públicas: aplicado às licitações e contratações de obras públicas. São Paulo: Pini, 2013.

BRASIL. [Constituição (1988)]. Constituição da República Federativa do Brasil de 1988.

Brasília, DF: Presidência da República, 1988. Disponível em: http://www.planalto.gov.br/ ccivil_03/constituicao/constituicaocompilado.htm. Acesso em: 15 jan. 2017.

BRASIL. Lei Complementar $\mathbf{n}^{\circ}$. 101, de 4 de maio de 2000. Estabelece normas de finanças públicas voltadas para a responsabilidade na gestão fiscal e dá outras providências. Brasília, DF: Presidência da República, 2000. Disponível em: http://www.planalto.gov.br/ccivil_03/ leis/LCP/Lcp101.htm. Acesso em: 17 mar. 2017.

BRASIL. Lei Federal n ${ }^{\circ}$. 12.309, de 9 de agosto de 2010. Dispõe sobre as diretrizes para a 
elaboração e execução da Lei Orçamentária de 2011 e dá outras providências. Brasília, DF: Presidência da República, 2010a. Disponível em: http://www.planalto.gov.br/ccivil_03/_ ato2007-2010/2010/lei/12309.htm. Acesso em: 17 mar. 2017.

BRASIL. Tribunal de Contas da União. Acórdão nº $560 / 2010$. Plenário. Relator: Ministro Augusto Nardes. Sessão de 24/3/2010. 2010b. Disponível em: https:/contas.tcu.gov.br/sagas/ SvlVisualizarRelVotoAcRtf?codFiltro=SAGAS-SESSAO-ENCERRADA\&seOcultaPagin $\mathrm{a}=\mathrm{S} \&$ item0=32781. Acesso em: $15 \mathrm{jan} .2017$.

BRASIL. Lei $\mathrm{n}^{\circ}$ 12.462, de 4 de agosto de 2011. Institui o Regime Diferenciado de Contratações Públicas - RDC; altera a Lei no 10.683 , de 28 de maio de 2003, que dispõe sobre a organização da Presidência da República e dos Ministérios, a legislação da Agência Nacional de Aviação Civil (Anac) e a legislação da Empresa Brasileira de Infraestrutura Aeroportuária (Infraero); [...]. Brasília, DF: Presidência da República, 2011a. Disponível em: http://www. planalto.gov.br/ccivil_03/_Ato2011-2014/2011/Lei/L12462.htm. Acesso em: 11 mar. 2017.

BRASIL. Decreto ${ }^{\circ}$. 7581/2011. Regulamenta o Regime Diferenciado de Contratações Públicas - RDC, de que trata a Lei ${ }^{\circ} 12.462$, de 4 de agosto de 2011. Brasília, DF: Presidência da República, 2011b. Disponível em: http://www.planalto.gov.br/ccivil_03/_ato20112014/2011/decreto/d7581.htm. Acesso em: 17 jan. 2017.

BRASIL. Tribunal de Contas da União. Secretaria-Geral de Controle Externo. Glossário de Termos do Controle Externo. 2012a. Disponível em: http://portal.tcu.gov.br/lumis/portal/file/fileDownload.jsp?fileId= 8A8182A14DB4AFB3014DBAC9E2994CFD. Acesso em: 15 jan. 2017.

BRASIL. Tribunal de Contas da União. Acórdão no . 2528/2012. Plenário. Relator: Ministro-Substituto André de Carvalho. Sessão de 19/09/2012. 2012b. Disponível em: https:/contas. tcu.gov.br/sagas/SvlVisualizarRelVotoAcRtf?codFiltro=SAGAS-SESSAO-ENCERRADA \&seOcultaPagina $=S \&$ item0 $=425361$. Acesso em: 15 jan. 2017.

BRASIL. Tribunal de Contas da União. Acórdão nº 2080/2012. Plenário. Relator: Ministro José Jorge. Sessão de 08/08/2012. 2012c. Disponível em: https://contas.tcu.gov.br/sagas/Svl VisualizarRelVotoAcRtf?codFiltro=SAGAS-SESSAO-ENCERRADA\&seOcultaPagina = S\&item0=415027. Acesso em: 11 mar. 2017.

BRASIL. Tribunal de Contas da União. Acórdão nº 306/2013. Plenário. Relator: Ministro Valmir Campelo. Sessão de 27/02/2013. Disponível em: https://contas.tcu.gov.br/sagas/Sv IVisualizarRelVotoAcRtf?codFiltro=SAGAS-SESSAO-ENCERRADA\&seOcultaPagina $=S \&$ item $0=449211$. Acesso em: 11 mar. 2017.

BRASIL. Supremo Tribunal Federal. Petição Inicial na Ação Direta de Inconstitucionalidade n.4.645/DF. Relator: Luiz Fux, de. Disponível em: http://redir.stf.jus. br/estfvisualizadorpub/jsp/consultarprocessoeletronico/ConsultarProcessoEletronico. jsf?seqobjetoincidente $=4131802$. Acesso em: 15 jan. 2017a. 
BRASIL. Ministério da Transparência, Fiscalização e Controladoria Geral da União - CGU. Relatório de Auditoria OS no. 201505075. Disponível em: http://auditoria.cgu.gov.br/ public/relatorio/consultar.jsf?rel=9107. Acesso em: 11 mar. 2017b.

BRASIL. Tribunal de Contas da União. Relatório do Acórdão 306/2017. Disponível em: http://sinaenco.com.br/arquivos-site/Acordao-TCU-306-2017.pdf. Acesso em: 11 mar. 2017c.

BRISSET, Karine; NAEGELEN, Florence. Why the reserve price should not be kept secret. Topics in Theoretical Economics, v. 6, n. 1, p. 1-17, 2006.

CAMMAROSANO, Márcio. Artigos $5^{\circ}$ a $7^{\circ}$ da Lei no 12.462, de 5 de agosto de 2011. In: CAMMAROSANO, Márcio; DAL POZZO, Augusto Neves; VALIM, Rafael (coord.). Regime Diferenciado de Contratações Públicas - RDC (Lei n ${ }^{\circ} 12.462 / 11$; Decreto ${ }^{\circ}$ 7.581/11): aspectos fundamentais. 3. ed. Belo Horizonte: Fórum, 2014.

CARDOSO, André Guskow. O Regime Diferenciado de Contratações Públicas: a questão da publicidade do orçamento estimado. In: JUSTEN FILHO, Marçal; PEREIRA, Cesar A. Guimarães (coord.). O regime diferenciado de contratações públicas (RDC): comentários à Lei ${ }^{\mathrm{o}} 12.462$ e ao Decreto no 7.581. Belo Horizonte: Fórum, 2014.

FERREIRA, Daniel; SANTOS, José Anacleto Abduch. Licitações para a Copa do Mundo e as Olimpíadas - Comentários sobre algumas inovações da Lei n ${ }^{\circ}$ 12.462/11. Revista Zênite - Informativo de Licitações e Contratos (ILC), Curitiba, n. 216, p. 171-183, fev. 2012. JUSTEN FILHO, Marçal. Comentários ao RDC (Lei 12.462/2011 e Decreto 7.581/2011). São Paulo: Dialética, 2013.

MARINELA, Fernanda. Direito Administrativo. Niterói: Impetus, 2013.

PEREIRA, Luiz Carlos Bresser. Gestão do setor público: estratégia e estrutura para um novo Estado. In: PEREIRA, Luiz Carlos Bresser; SPINK, Peter (org.). Reforma do Estado e Administração Pública Gerencial. 4. ed. Rio de Janeiro: Fundação Getúlio Vargas, 1998. ROSENKRANZ, Stephanie; SCHMITZ, Patrick. Reserve prices in auctions as reference points. The Economic Journal, n. 117, p. 637-653, Apr. 2007.

SANCHEZ-GRAELLS, Albert. The difficult balance between transparency and competition in publicprocurement: some recent trends in the case law of the European Courts and a look at the new directivesUniversity of Leicester School of Law Research Paper No. 13-11. 2013. Available at SSRN: https://ssrn.com/abstract=2353005. Access in: 11 Mar. 2017.

SILVA, Ângelo Henrique Lopes da. Preço de Reserva em Licitações Públicas. Finanças Públicas - XVI Prêmio Tesouro Nacional. 2011. p. 8-11. Disponível em: http:// www.tesouro.fazenda.gov.br/documents/10180/137713/Premio2011_Tema_2_3.pdf. Acesso em: 12 jun. 2018. 
TREUTEL, Claudia Simone da Rosa. A Constitucionalidade do Sigilo do Orçamento na Lei 12.462/11. Revista Jurídica da Procuradoria-geral do DF, Brasília, p. 121-132, jul./dez. 2014. ZYMLER, Benjamin. DIOS, Laureano. O Regime Diferenciado de Contratação - RDC. 2. ed. Belo Horizonte: Fórum, 2013.

\section{NOTA}

O artigo intitulado A CONTTRIBIÇÃO DO ORÇAMENTO SIGILOSO PARA A EFICIÊNCIA DAS LICITAÇÕES E CONTRATAÇÕES PÚBLICAS: uma análise a partir das decisões do TCU foi produzido como trabalho de conclusão da disciplina Reforma da Administração Pública, ministrada pelo Professor Dr. Marcelo Dias Varella no Programa de Mestrado em Direito do UNICEUB. Os dois autores contribuíram para a redação do texto, sendo que a parte principal foi desenvolvida pelo primeiro autor, João Paulo Forni, sob orientação do professor da disciplina. 